\section{Screening for Depression}

To the Editor:-For busy practitioners the prospect of using a two-question instrument for assessing depression, as proposed by Whooley et al. in the July 1997 issue, ${ }^{1}$ is welcomed. However, we take issue with the authors in two areas. First, the strength of this study is in screening for depression (excluding it), not in "case finding" (identifying depression). The likelihood ratio negative $\left(\mathrm{LR}^{-}\right)$of 0.07 for the two-question instrument is at least the same, if not better, than all others cited. Consider a patient with two different pretest probabilities of depression based on different prevalence rates (Table 1). ${ }^{1,2}$ It is highly likely the clinician will conclude the patient is not depressed (negative responses) in that the posttest probabilities are 0.02 and 0.05 , respectively. Conversely, it is doubtful clinicians would be willing to treat a patient who answers both questions positively, despite the fact that posttest probabilities are 0.33 and 0.63 . Further testing and evaluation with more specific instruments seem appropriate. Second, the authors make a case to exclude drug and alcohol abuse in order to decrease the false-positive rate and increase the $\mathrm{LR}^{+}$. They chose two or more positive responses as a cutoff for the CAGE screening instrument. Based on original data by Buchsbaum et al., ${ }^{3}$ with revisions provided in a letter to the editor, ${ }^{4}$ the $\mathrm{LR}^{+}$for $>0,>1,>2$, and $>3$ positive responses was $4.7,8.2,22$, and 95 , respectively. For a pretest probability of 0.25 for alcoholism, the likelihood of alcoholism increases to 0.58 with only one positive response. For $>1,>2$, and $>3$ responses, the posttest probability increases to $0.73,0.88$, and 0.97 , respectively. If it is appropriate to exclude alcoholic patients, we recommend choosing a cutoff of 3 of $4(>2)$

Table 1. Value of "Two-Question" Instrument in Depression at Different Prevalence Rates Based on Likelihood Ratio Positive (2.2) and Likelihood Ratio Negative (0.07) from Whooley et al.

\begin{tabular}{lccc}
\hline \hline & $\begin{array}{c}\text { Pretest } \\
\text { Probability: } \\
\text { Prevalence }\end{array}$ & $\begin{array}{c}\text { Posttest } \\
\text { Probability: } \\
\text { Negative Test }\end{array}$ & $\begin{array}{c}\text { Posttest } \\
\text { Probability: } \\
\text { Positive Test }\end{array}$ \\
\hline Whooley et al. $^{1}$ & 0.18 & 0.02 & 0.33 \\
Smith et al. $^{2}$ & 0.44 & 0.05 & 0.63 \\
\hline
\end{tabular}

JGIM welcomes your letters and comments. Letters may contain brief commentaries on articles published in the Journal, illustrative case reports, general suggestions for improving the Journal, or other information of interest to readers. Letters to the Editor should not exceed 450 words in length and should be sent in triplicate (typed, double-spaced). We cannot guarantee publication and we may edit to improve readability.

You may send your letters to us by mail, fax, or e-mail: JGIM, Veterans Affairs Medical Center (JGIM-111), University and Woodland Avenues, Philadelphia, PA 19104; fax: 215-8234450; e-mail:jgim@mail.med.upenn.edu. or 4 of 4 positive responses.-David A. NARdone, MD, and SuSAN P. SмIтн, MD, Veterans Health Administration, Portland, Ore.

\section{REFERENCES}

1. Whooley MA, Avins AL, Miranda J, Browner WS. Case-finding instruments for depression: two questions are as good as many. J Gen Intern Med. 1997;12:439-45.

2. Smith SP, Joos SK, Hickam DH, Emerson J, Atkinson RM. Final report of the Medicine-Psychiatry Program (MPP), VAMC Portland 1989-1993. Jointly sponsored by VHA Western Region and Mental Health \& Behavioral Sciences Service, VA Central Office, Portland, Ore.

3. Buchsbaum DG, Buchanan RG, Centor RM, Schnoll SH, Lawton MJ. Screening for alcohol abuse using CAGE scores and likelihood ratios. Ann Intern Med. 1991;115:774-7.

4. Nardone DA. Interpreting CAGE scores. Ann Intern Med. 1992; 116:1032. Letter.

In reply:-Drs. Nardone and Smith appear to share a common confusion regarding the definitions of screening and case finding. Sackett and Holland define screening as "the testing, not of carefully selected population samples, but of apparently healthy volunteers from the general population for the purpose of separating them into groups with high and low probabilities for a given disorder." Case finding, on the other hand, is defined as "the testing of patients who have sought health care for disorders which may be unrelated to their chief complaints. The encounter is initiated by the patient and the purpose here is a comprehensive assessment of health."

Although many argue that screening for depression may benefit the general population, neither the U.S. Preventive Services Task Force nor the Canadian Task Force on the Periodic Health Examination has found sufficient evidence to recommend the routine use of screening questionnaires for depression in primary care patients. ${ }^{2,3}$ We believe the two questions should be used by primary care providers as a case-finding measure to assist in identifying patients who should undergo a more complete assessment for depression. However, because of its low positive predictive value even in populations with a high prevalence of depression, we emphasized, as do Drs. Nardone and Smith, that patients who answer yes to either of the two questions need further evaluation to confirm the diagnosis of depression.

We reported our results both including and excluding patients with substance abuse because we were concerned that the high prevalence of substance abuse in veterans (33\% in our sample) might render our findings less generalizable to non-VA populations. We used a score of 2 or greater on the CAGE questionnaire to identify patients with alcoholism. ${ }^{4}$ Drs. Nardone and Smith suggested it might be more appropriate to use a cutpoint of 3 or 4 (Table 1). Use of a stricter definition of alcoholism slightly decreased the specificity and positive predictive value of the twoquestion instrument toward the $57 \%$ specificity found when patients with substance abuse were included in the analysis, but the sensitivity and negative predictive value were not substantially affected.-Mary A. Whooley, MD, ANDrew L. Avins, MD, MPH, Jeanne Miranda, PhD, and WARren S. Browner, MD, MPH, San Francisco (Calif.) VA Medical Center. 
Table 1. Test Characteristics of the Two-Question Instrument for Depression, Excluding Subjects with Substance Abuse, Using CAGE Score to Identify Subjects with Alcohol Abuse*

CAGE Score

Used to Identify

Alcoholism

Sensitivity, Specificity, Likelihood Ratio

2 or greater

3 or greater

\begin{tabular}{cccc}
$\%$ & $\%$ & Positive & Negative \\
96 & 66 & 2.8 & 0.06 \\
96 & 63 & 2.6 & 0.06 \\
97 & 62 & 2.2 & 0.05 \\
\hline
\end{tabular}

*Based on data from Whooley et al. ${ }^{5}$

\section{REFERENCES}

1. Sackett DL, Holland WW. Controversy in the detection of disease. Lancet. 1975;2:357-9.

2. Canadian Task Force on the Periodic Health Examination. Periodic health examination, 1990 update, 2: early detection of depression and prevention of suicide. Can Med Assoc J. 1990;142:1233-8.

3. U.S. Preventive Services Task Force. Guide to Clinical Preventive Services, 2nd ed. Baltimore, Md: Williams and Wilkins; 1996.

4. Mayfield D, McLeod G, Hall P. The CAGE questionnaire: validation of a new alcoholism screening instrument. Am J Psychiatry. 1974; 131:1121-3.

5. Whooley MA, Avins AL, Miranda J, Browner WS. Case-finding instruments for depression: two questions are as good as many. J Gen Intern Med. 1997;12:439-45.

\section{ANNOUNCEMENT}

\section{SGIM Website}

Please visit the Society of General Internal Medicine on their World-Wide Website. SGIM is located at http://www.sgim.org 